\title{
Determining Sex of Magellanic Penguins Using Molecular Procedures and Discriminant Functions
}

\author{
Marcelo Bertellotti ${ }^{1}$, José L. Tella ${ }^{2}$, José A. GodoY ${ }^{3}$, Guillermo Blanco ${ }^{4}$, \\ MANuela G. Forero ${ }^{5}$, José A. DonÁzAR ${ }^{2}$ AND Olga CEBAllos ${ }^{6}$ \\ ${ }^{1}$ Centro Nacional Patagónico (CONICET), Brown 3500, U9120ACV Puerto Madryn Chubut, Argentina \\ Internet: bertello@cenpat.edu.ar \\ ${ }^{2}$ Department of Applied Biology, Estación Biológica de Doñana (CSIC), Av. de Ma Luisa s/n \\ Pabellón del Perú, 41013 Sevilla, Spain \\ ${ }^{3}$ Laboratory of Molecular Ecology, Estación Biológica de Doñana (CSIC), Av. de Ma Luisa s/n \\ Pabellón del Perú, 41013 Sevilla, Spain
}

\begin{abstract}
${ }^{4}$ Instituto de Investigación en Recursos Cinegéticos (CSIC-UCLM), Ronda de Toledo s/n 13005 Ciudad Real, Spain
${ }^{5}$ Instituto Mediterráneo de Estudios Avanzados (CSIC-UIB), Department of Natural Resources 07190 Esporles, Mallorca, Spain

${ }^{6}$ Grupo de Estudios Biológicos Ugarra, Carlos III 19 4-I, 31002 Pamplona, Spain
\end{abstract}

\begin{abstract}
Magellanic Penguins (Spheniscus magellanicus) show little sexual dimorphism, and although males are usually larger than females, sexing by direct observation may be difficult, especially in the case of chicks. In this paper we evaluate the utility of four different PCR-based sex determination techniques using genomic DNA for sexing Magellanic Penguins. We found that the primer set designed for sex determination in Collared Flycatcher (Ficedula albicollis) also provided a reliable, simple and convenient sexing procedure for Magellanic Penguins. Additionally, we obtained discriminant functions for sexing adults and chicks, sampled at six colonies differing in size and other ecological characteristics. Discriminant function for adults used two variables, bill length and bill depth that correctly classified $97 \%$ of the birds. Discriminant function for chicks included bill length and flipper length and correctly classified $78 \%$ of the individuals. Although molecular and biometric approaches could be useful for sexing adult Magellanic Penguins, only molecular procedures proved appropriate for accurately sexing chicks. Received 24 March 2002, accepted 5 August 2002.
\end{abstract}

Key words.-Magellanic penguins, Spheniscus magellanicus, DNA, sexing birds, discriminant functions.

Knowledge of the sex of individuals is an important requirement in many field studies, but it is difficult for monomorphic species such as most seabirds. Penguins show little sex-linked size and plumage dimorphism, and although males are usually bigger than females (Martínez 1992; Agnew and Kerry 1995), changes with age and overlap in size between members of a pair make sexing by direct observation difficult (Scolaro et al. 1983; Amat et al. 1993). For several penguin species, the sex has been estimated by observing copulation (Scolaro et al. 1990), cloacal examination (Boersma and Davies 1987; Gales 1988; Renner et al. 1998; Renner and Davies 1999), or dissection (Scolaro et al. 1983; Scolaro 1987; Zavalaga and Paredes 1997). In addition, in some studies discriminant functions have been developed for sex determination derived from biometric data (Amat etal. 1993; Renner etal. 1998).

The Magellanic Penguin (Spheniscus magellanicus) is a slightly dimorphic seabird widely distributed along the Patagonian coast of Argentina (Yorio et al. 1998). Discriminant functions obtained from biometry of individuals of known sex have been the commonest method of sexing adult Magellanic Penguins, since two discriminant functions, obtained in two colonies, are available for sexing adults (Scolaro et al. 1983; Gandini et al. 1992). However, numerous studies have shown geographic body size variation for other penguin species inhabiting a wide geographical area (Renner et al. 1998; Renner and Davis 1999), which may limit the applicability of discriminant models to colonies or localities where the functions were ob- 
tained (Coulson et al. 1983; Evans et al. 1993; Mawhinney and Diamond 1999).

A potential alternative for accurately sexing penguins is the recently developed DNAbased methods (reviewed in Ellegren and Sheldon 1997). Among these, PCR-based methods targeting CHD1-Z and CHD1-W genes are purported to be of universal application to birds, with the exception of ratite species. Different primer sets have been designed for amplifying different portions of CHD1 genes. Amplification products coming from CHD1-Z and CHD1-W are later distinguished through different technical procedures. The procedure used affects the level of technical expertise demanded, relative cost, and applicability to large number of samples. Although some genetic procedures have been applied to some species of penguins (Dubach 1996), these techniques have not been tested for Magellanic Penguins.

The main objective of this paper was to evaluate the utility of four different molecular procedures for sexing Magellanic Penguins. Additionally, we obtained discriminant functions derived from both adults and chicks previously sexed by DNA. These birds were sampled at six colonies of different size and ecological characteristics, and thus the discriminant functions could be applied to a wide range of the species' distributions.

\section{METHODS}

During January, 1999 we randomly sampled Magellanic Penguins adults and chicks at six breeding colonies on the Patagonian coast of Argentina: San Lorenzo (42 $\left.{ }^{\circ} 05^{\prime} \mathrm{S}, 6^{\circ} 51^{\prime} \mathrm{W}\right)$, Asentamiento Oeste (42 $06^{\prime} \mathrm{S}$, $\left.63^{\circ} 56^{\prime} \mathrm{W}\right)$, Isla Primera (Caleta Valdés) $\left(42^{\circ} 21^{\prime} \mathrm{S}\right.$, $\left.63^{\circ} 37^{\prime} \mathrm{W}\right)$, Caleta Interna (42 $\left.27^{\prime} \mathrm{S}, 63^{\circ} 36^{\prime} \mathrm{W}\right)$, Punta

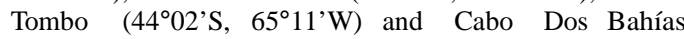

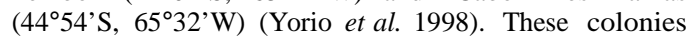
were located along $500 \mathrm{~km}$ of coastline and colony size varied from 483 to 175,000 pairs, thus satisfactorily covering the range of colony size for the species (Tella et al. 2001; for a detailed description of these colonies see Yorio et al. 1998). Chicks were sampled when they were about 70 days old $(68.1 \pm 7.0)$, just few days before leaving the nests (for sampling details see Tella et al. 2001; Forero et al. 2001; Forero et al. 2002; Forero et al. in press). Both adults and chicks were weighed on a spring balance to the nearest $25 \mathrm{~g}$. Bill length and bill depth were measured as described by Scolaro et al. (1983), with a digital calliper to the nearest $0.01 \mathrm{~mm}$. Flipper length was measured to the nearest $\mathrm{mm}$ from the humero-radial joint to the tip of the flipper (as by Zavalaga and Paredes 1997) with a ruler.

\section{Molecular Sexing}

A drop of blood was taken by venipuncture of the brachial or foot veins, and stored in 1-ml ethanol. Crude DNA extract was prepared by boiling $5 \mu \mathrm{l}$ of the blood/ ethanol mixture in $100 \mu \mathrm{l}$ of a $100 \mathrm{mM} \mathrm{NaOH}$ solution for $10 \mathrm{~min}$. After centrifugation, $0.5 \mu \mathrm{l}$ of the supernatant was used directly as template in PCR.

PCR was performed in a final volume of $25 \mu \mathrm{l}$ containing $67 \mathrm{mM}$ Tris- $\mathrm{HCl} \mathrm{pH} 8.8,16 \mathrm{mM}\left(\mathrm{NH}_{4}\right)_{2} \mathrm{SO}_{4}, 3.5$ $\mathrm{mM} \mathrm{MgCl}_{2}, 0.01 \%$ Tween-20, $0.01 \%$ gelatin, $0.2 \mathrm{mM}$ each dNTP, $0.2 \mu \mathrm{M}$ each primer, and $0.5 \mathrm{U}$ of Taq DNA polimerase. The thermal profile comprised an initial denaturation step of $94^{\circ} \mathrm{C}$ for $2 \mathrm{~min}$, followed by a single cycle of $2 \mathrm{~min}$ at $94^{\circ} \mathrm{C}, 30 \mathrm{~s}$ at $55^{\circ} \mathrm{C}$ and $1 \mathrm{~min}$ at $72^{\circ} \mathrm{C}$, and 34 cycles of $30 \mathrm{~s}$ at $92^{\circ} \mathrm{C}, 30 \mathrm{~s}$ at $50^{\circ} \mathrm{C}, 45 \mathrm{~s}$ at $72^{\circ} \mathrm{C}$. A final extension step of $72^{\circ} \mathrm{C}$ for 5 min was added after the last cycle. The same cycling parameters were used with all primer sets. Twenty $\mu \mathrm{l}$ of the PCR reaction was analyzed by electrophoresis in a $2 \%$ or $3 \%$ agarose gel containing $0.5 \mu \mathrm{g} / \mathrm{ml}$ ethidium bromide. PCR products were examined and photographed under UV light.

\section{Statistical Analyses}

After knowing the sex of all the birds from molecular analyses, we performed two-way ANOVAs to study colony (random effect) and sex (fixed effect) differences in body size of adults and chicks separately. We derived discriminant functions (separately for adults and chicks) using DISCRIM procedure of the SAS System program (version 6.12). In some previous cases, discriminant functions were tested against the same sample from which it was derived and not from an independent sample, resulting in an exaggerated effectiveness. To avoid this, we applied a jackknife procedure (Amat et al. 1993), in which each individual in the sample was classified using a discriminant function derived from the total sample, excluding the individual being classified (Chardine and Morris 1989; Amat et al. 1993). This algorithm chooses the function that had the lowest percentage of misclassification. Values reported are means $\pm S D$.

We took precautions to avoid handling and labeling errors, and we repeated every individual assay for which diagnostic bands were not clearly seen. In addition, we repeated assays for 48 chicks and 60 adults chosen at random and obtained the same result in all cases.

\section{RESULTS}

\section{Molecular Sexing}

Primers 2917F/3088R (Ellegren 1996), P2/P8 (Griffiths et al. 1998) and 2550F/ 2718R (Fridolfsson and Ellegren 1999), designed to detect intronic size differences, were all tested initially on four breeding pairs whose members showed large size differences, and whose sex could therefore be confidently determined. The three primer pairs designed to amplify intron-spanning sequences successfully amplified fragments 
from Magellanic Penguins, although their utility for gender determination varied. Both P2/P8 and 2917F/3088R yielded the expected patterns consisting of two bands from females and only one from males. The estimated sizes of the bands were 490 and 470 bp for $2917 \mathrm{~F} / 3088 \mathrm{R}$, and 360 and 380 bp for $\mathrm{P} 2 / \mathrm{P} 8$, for $\mathrm{Z}$ and $\mathrm{W}$ genes respectively. Such small differences required long runs on $3 \%$ agarose gels to be adequately resolved, but proved sufficient for the application of these methods to Magellanic Penguins in a relatively simple procedure. A single band was obtained with primer 2550F/2718R from both males and females, indicating that sizes of the products from CHD1-Z and CHD1-W genes were identical, or too close to be adequately resolved by these gels. The use of these primers for sex determination in this species would require different electrophoretic conditions or the differentiation of both products based on sequence differences. We also tested an alternative approach originally used by Ellegren (1996) to sex Collared Flycatcher (Ficedula albicollis). He designed a primer (cfR) to match an intronic sequence specific of the CHD-W gene, which when used in combination with primer $2945 \mathrm{~F}$ yields a $210 \mathrm{bp}$ W-specific band. On the other hand, a third primer 3224R, together with 2945F yields a band of 630 bp from both genes (sizes correspond to Collared Flycatcher, Ellegren 1996). This primer set amplified products of similar sizes in Magellanic Penguin. A 210 bp W-specific fragment was obtained only from females, while a 680 bp fragment was obtained from both males and females. Both bands were readily resolved by simple agarose gel electrophoresis, resulting in a simple, convenient and low-cost method for sexing Magellanic Penguins.

We tested the reliability of the assay based on primers 2945F, cfR and 3224R by applying it to a subset of 32 breeding pairs for which sex could be confidently assigned based on morphology. In all pairs, one individual was identified as male and the other as female, with the larger bird always sexed as male. We therefore applied these molecular methods for sex determination of 331 adults and 266 chicks from six different colonies, which provided the sample set for discriminant functions.

\section{Discriminant Functions}

We found significant effects of both colony and sex on adult body mass and bill depth, while bill length and flipper length only differed between sexes (Table 1 , see also Forero et al. 2001). Male chicks were also significantly larger in all morphometric measurements than females (Table 1). We found differences in chick bill length, bill depth and flipper length between sexes but not among colonies, while we found differences in body mass among colonies but not between sexes (Table 1).

The parameter that gave the best single factor correlation with sex was bill depth (canonical correlation 0.838), and the discriminant function with only this variable classified correctly $94.9 \%$ of the cases. On the other hand, bill length considered as the only variable correctly classified $85.5 \%$ of the cases (canonical correlation 0.721 ). The better discriminant function using jack-knife procedure for adults included three variables: bill length, bill depth and body mass (all P-values <0.001). However, the model excluding body mass classified correctly a higher number of individuals (canonical correlation 0.857) and thus we selected the following function:

$$
\begin{gathered}
D_{1}=-85.7425+2.4267 * \text { bill depth }+ \\
0.5653 * \text { bill length }
\end{gathered}
$$

Where an adult bird would be male if $\mathrm{D}_{1}>0$ and female if $D_{1}<0$. This discriminant function correctly classified $97.0 \%$ of the adult individuals ( $\mathrm{N}=331$ ) sexed using molecular techniques (95\% of 192 males and 99\% of 139 females), improving functions previously obtained by Scolaro et al. (1983) and Gandini et al. (1992) in five out of our six study colonies (Table 2).

The parameter that gave the best single factor correlation with sex of chicks was flipper length (canonical correlation 0.544), and the discriminant function obtained with only this variable classified correctly $73.7 \%$ 
Table 1. Mean values ( \pm SD, sample size) of morphometric variables for male and female Magellanic Penguins from Patagonia, Argentina, sexed by molecular procedures. Differences in measurements were tested using two-way ANOVAs, with sex as a fixed effect and colony as a random effect. All measurements in mm except body mass, presented in grams.

\begin{tabular}{|c|c|c|c|c|}
\hline \multirow[b]{2}{*}{ Variable } & \multirow[b]{2}{*}{ Males } & \multirow[b]{2}{*}{ Females } & \multicolumn{2}{|c|}{ Two-way ANOVA } \\
\hline & & & Colonies & Sex \\
\hline \multicolumn{5}{|l|}{ Adults } \\
\hline Bill length & $\begin{array}{c}58.7 \pm 2.4 \\
\quad(192)\end{array}$ & $\begin{array}{l}53.8 \pm 2.3 \\
\quad(139)\end{array}$ & $\begin{array}{c}\mathrm{F}_{5,319}=1.5 \\
\mathrm{~ns}\end{array}$ & $\begin{array}{c}\mathrm{F}_{1,319}=294.6 \\
\mathrm{P}<0.001\end{array}$ \\
\hline Bill depth & $\begin{array}{c}24.0 \pm 1.2 \\
\quad(192)\end{array}$ & $\begin{array}{l}20.5 \pm 1.0 \\
\quad(139)\end{array}$ & $\begin{array}{c}\mathrm{F}_{5,319}=10.3 \\
\mathrm{P}<0.02\end{array}$ & $\begin{array}{c}\mathrm{F}_{1,319}=1293.4 \\
\mathrm{P}<0.001\end{array}$ \\
\hline Flipper length & $\begin{array}{c}166.9 \pm 6.6 \\
(189)\end{array}$ & $\begin{array}{c}158.6 \pm 6.3 \\
(133)\end{array}$ & $\begin{array}{c}\mathrm{F}_{5,310}=3.8 \\
\mathrm{~ns}\end{array}$ & $\begin{array}{c}\mathrm{F}_{1,310}=69.8 \\
\mathrm{P}<0.001\end{array}$ \\
\hline Body mass & $\begin{array}{c}4501 \pm 402 \\
(183)\end{array}$ & $\begin{array}{c}3708 \pm 355 \\
(129)\end{array}$ & $\begin{array}{c}\mathrm{F}_{5,300}=5.79 \\
\mathrm{P}<0.05\end{array}$ & $\begin{array}{c}\mathrm{F}_{1,300}=536.9 \\
\mathrm{P}<0.001\end{array}$ \\
\hline \multicolumn{5}{|l|}{ Chicks } \\
\hline Bill length & $\begin{array}{l}47.0 \pm 2.6 \\
\quad(143)\end{array}$ & $\begin{array}{l}45.4 \pm 2.0 \\
\quad(123)\end{array}$ & $\begin{array}{c}\mathrm{F}_{5,254}=0.7 \\
\mathrm{~ns}\end{array}$ & $\begin{array}{c}\mathrm{F}_{1,254}=6.8 \\
\mathrm{P}<0.05\end{array}$ \\
\hline Bill depth & $\begin{array}{c}15.8 \pm 1.1 \\
(143)\end{array}$ & $\begin{array}{l}14.7 \pm 1.0 \\
(123)\end{array}$ & $\begin{array}{c}\mathrm{F}_{5,254}=4.0 \\
\mathrm{~ns}\end{array}$ & $\begin{array}{c}\mathrm{F}_{1,254}=47.0 \\
\mathrm{P}<0.001\end{array}$ \\
\hline Flipper length & $\begin{array}{c}165.6 \pm 5.6 \\
(143)\end{array}$ & $\begin{array}{c}158.3 \pm 5.7 \\
(123)\end{array}$ & $\begin{array}{c}\mathrm{F}_{5,254}=3.3 \\
\mathrm{~ns}\end{array}$ & $\begin{array}{c}\mathrm{F}_{1,254}=81.1 \\
\mathrm{P}<0.001\end{array}$ \\
\hline Body mass & $\begin{array}{c}3011 \pm 566 \\
(141)\end{array}$ & $\begin{array}{c}2709 \pm 519 \\
(122)\end{array}$ & $\begin{array}{c}\mathrm{F}_{5,251}=9.1 \\
\mathrm{P}<0.02\end{array}$ & $\begin{array}{c}\mathrm{F}_{1,251}=4.6 \\
\mathrm{~ns}\end{array}$ \\
\hline
\end{tabular}

of the cases. The second single factor was bill depth (canonical correlation 0.446), and the discriminant function obtained with this variable classified correctly $70.3 \%$ of the cases. The best discriminant function obtained for chicks $(\mathrm{N}=266)$ included flipper length and bill depth (all P-values < 0.001). The resulting function was:

$$
\begin{aligned}
\mathrm{D}_{2}= & -42.47+0.6869 * \text { bill depth }+ \\
& 0.1976 * \text { flipper length }
\end{aligned}
$$

A chick would be a male if $D_{2}>0$, and female if $\mathrm{D}_{2}<0$. This function correctly classified $78 \%$ of the sexed chicks ( $78 \%$ of 143 males and $78 \%$ of 123 females).

\section{DISCUSSION}

Molecular procedures show clear advantages than more conventional methods such as behavioral observations, cloacal examination, and internal observation of gonads. Dissection obviously involves killing the individuals, thus being ethically questionable. Sexing penguins through behavioral observations, such as copulation position (Scolaro et al. 1990), is restricted to a small window of the breeding season. The use of vent measurements, which in Magellanic Penguins correctly predicted the sex of $92 \%$ of the individuals, is also restricted to a short period (few days after egg-laying) and only applicable to breeding adults (Boersma and Davies 1987). Gonadal inspection through laparoscopy requires surgery and usually works only

Table 2. Percentage of adult Magellanic Penguins sexed by DNA (192 males and 139 females) and later correctly sexed by A) our morphometric discriminant function, and by those previously published by B) Scolaro et al. $1983(22.17 *$ bill depth $+7.73 *$ bill length -95.4$)$, and C) Gandini et al. 1992 (if bill depth > 22.3, male, if not, female). The functions best classifying the sex of penguins for each colony and for the whole sample are shown in bold.

\begin{tabular}{lccc}
\hline \hline Colony & $\mathrm{A}$ & $\mathrm{B}$ & $\mathrm{C}$ \\
\hline Asentamiento Oeste & $\mathbf{1 0 0}$ & 92.6 & 92.6 \\
San Lorenzo & $\mathbf{9 7 . 2}$ & 88.9 & 91.7 \\
Isla Primera & $\mathbf{9 4 . 2}$ & 88.5 & 90.4 \\
Caleta Interna & 98.4 & 88.5 & $\mathbf{1 0 0}$ \\
Punta Tombo & $\mathbf{9 4 . 4}$ & 90.0 & 93.3 \\
Cabo Dos Bahías & $\mathbf{1 0 0}$ & 92.3 & 96.9 \\
Total & $\mathbf{9 7 . 0}$ & 90.0 & 94.3 \\
\hline
\end{tabular}


for sexually mature individuals (M. A. Quevedo, pers. comm.). All of the above methods are only useful for breeding birds, and during particular periods of the year. Karyotype analysis extends the possibility of sexing any individual independent of age and sampling date, but with the constraint of needing a blood cell culture (Dubach 1996) that is more time-consuming that the molecular procedures we used here.

We tested four molecular assays for sexing Magellanic Penguins (Ellegren 1996; Griffiths et al. 1998; Fridolfsson and Ellegren 1999), finding that three of them work well for this species. Thus, molecular sexing is confirmed for the Magellanic Penguin. We found that the primer set originally designed for sex determination in the Collared Flycatcher (Ellegren 1996) was also useful for the Magellanic Penguin. This is surprising, since this assay was based on intronic sequences that tend to be highly variable among species. Low substitution rates in CDH1-W introns (Ellegren and Fridolfsson 1997), and the high magnesium concentrations, might contribute to the observed cross-amplification between highly divergent species. We have obtained similar results with other avian species (Balbontin et al. 2001; J. A. G., unpubl. results) indicating the method may have a wider application than previously suspected. This method was the simplest and most convenient for sexing Magellanic Penguins, requiring only a simple PCR and agarose gel electrophoresis. Furthermore, by combining quick DNA preparations with short runs in $1.5-2 \%$ agarose gels, a high output can be achieved with limited investment of labor or reagents. Although molecular techniques are often regarded as complicated, requiring technical expertise and expensive infrastructure, the particular protocol proposed here for sexing Magellanic Penguins involves simple techniques, requires limited infrastructure that is common and basic in any DNA analysis laboratory, and is relatively inexpensive.

Although we have found significant differences among colonies for several morphological measurements of Magellanic Penguin adults and chicks (see also Forero et al.
2001), we obtained a satisfactory discriminant function for sexing adult individuals. Our discriminant function technique is applicable to a wider geographic range than the two previously published techniques (Scolaro et al. 1983; Gandini et al. 1992), and slightly improves sex determination power, correctly classifying $97 \%$ of the adults overall. Therefore, this technique could be used for studies with large sample sizes, where the need for total accuracy is not imperative.

Our discriminant function can be applied satisfactorily to birds in colonies located between $42^{\circ}-45^{\circ} \mathrm{S}$, on the Atlantic coast. However, the species' range extends much further: to $55^{\circ} \mathrm{S}$ on the Atlantic coast, to the Falkland Islands and up to about $45^{\circ} \mathrm{S}$ on the Pacific coast (Martínez 1992). If Magellanic Penguins show extra geographic variation outside of our study area that would interfere with sexing by morphometrics, our discriminant function could be not applied to other colonies with the same accuracy as showed here.

On the other hand, although Scolaro (1987) found satisfactory functions for fledglings and yearlings (93\% and $97 \%$ of the cases correctly classified, respectively) for a single colony of Magellanic Penguins, there are no discriminant functions available for growing chicks in this species. Moreover, the reliability of sexing chicks through biometry might be questioned, since our discriminant function only classified correctly $78 \%$ of the birds. The low percentage of our classification invalidates its use in many cases (e.g., when studying sex allocation in birds), given that the actual brood sex ratio needs to be known (e.g., Ellegren and Sheldon 1997).

Although our discriminant functions based on morphometry might still prove useful with some limitation, we found molecular analysis to be the most reliable and effective method for sexing Magellanic Penguins. The usefulness of this technique is of importance in the development of ecological studies that imply the inclusion of sex as a potential factor causing variation in the phenomenum studied as have been showed in several studies carried out with this species (Forero et al. 2001; Tella et al. 2001; Forero 
etal. 2002; Forero etal. in press). More laboratory studies aimed at testing the validation of molecular procedures for sexing species with low degree of sexual dimorphism are required as a tool in ecological studies.

\section{ACKNOWLEDGMENTS}

We thank M. Ferrer and S. C. Griffith for comments on the manuscript, and to Fundación Patagonia Natural for the logistic support. We also thank Secretaría de Turismo y Areas Protegidas of Chubut Province and Dirección Nacional de Fauna y Flora Silvestre for the permits to conduct fieldwork. M. B. was supported by a grant from the Consejo Nacional de Investigaciones Cientifícas y Técnicas (CONICET) of Argentina. During fieldwork G. B. and M. G. F. joined a grant from the Ministerio de Educación y Ciencia of Spain in the Department of Biology of the University of Saskatchewan, Canada. This study was financially supported by funds from Caja General de Ahorros de Granada.

\section{LITERATURE CiTED}

Amat, J. A., J. Viñuela and M. Ferrer. 1993. Sexing Chinstrap Penguins (Pygoscelis antarctica) by morphological measurements. Colonial Waterbirds 16: 213-1-215.

Agnew, D. J. and K. R. Kerry. 1995. Sexual dimorphism in penguins. Pages 299-318 in The penguins (P. N. I. Normar and P. Reilly, Eds.). Beatty and Sons, Surrey.

Balbontin, J., M. Ferrer and E. Casado. 2001. Sex determination in Booted Eagles (Hieraaetus pennatus) using molecular procedures and discriminant function analysis. Journal of Raptor Research 35: 20-23.

Boersma, P. D. and E. M. Davies. 1987. Sexing monomorphic birds by vent measurements. Auk 104: 779-783.

Chardine, J. W. and R. D. Morris. 1989. Sexual size dimorphism and assortative mating in the Brown Noddy. Condor 91: 868-874.

Coulson, J. C. S., C. S. Thomas, J. E. L. Butterfield, N. Duncan, P. Monaghan and C. Shedden. 1983. The use of head and bill length to sex live gulls Laridae. Ibis 125: 549-557.

Dubach, J. 1996. Gender determination in captive and wild species of penguins. Penguin Conservation 9: 14-15.

Ellegren, H. 1996. First gene on the avian W chromosome (CHD) provides a tag for universal sexing of non-ratite birds. Proceedings of the Royal Society, London B. 263: 1635-1641.

Ellegren, H. and A. K. Fridolfsson. 1997. Male-driven evolution of DNA sequences in birds. Nature Genetics 17: 182-184.

Ellegren, H. and B. C. Sheldon. 1997. New tools for sex identification and the study of sex allocation in birds. Trends in Ecology and Evolution 12: 255-259.

Evans, D. R., E. M. Hoopes and C. R. Griffin. 1993. Discriminating the sex of Laughing Gulls by linear measurements. Journal of Field Ornithology 64: 1-9.

Forero, M. G., J. L. Tella, J. A. Donázar, G. Blanco, M. Bertellotti and O. Ceballos. 2001. Phenotypic assortative mating and within-pair sexual dimorphism and its influence on breeding success and offspring quality in Magellanic penguins. Canadian Journal of Zoology 79: 1414-1322.
Forero, M. G., K. A. Hobson, G. R. Bortolotti, J. A. Donázar, M. Bertellotti and G. Blanco. 2002. Food resource utilization by Magellanic penguins evaluated through stable isotope analysis: segregation by sex and age and influence of offspring quality. Marine Ecology Progress Series. 234: 289-299.

Forero, M. G., J. L. Tella, K. A. Hobson, M. Bertellotti and G. Blanco. Conspecific food competition explains variability in colony size: a test using stable isotopes in Magellanic penguins. Ecology. In press.

Fridolfsson, A. K. and H. Ellegren. 1999. A simple and universal method for molecular sexing of non-ratite birds. Journal of Avian Biology 30: 116-121.

Gales, R. P. 1988. Sexing adult Blue Penguins by external measurements. Notornis 35: 71-75.

Gandini, P., E. Frere and T. Holik. 1992. Implicancias de las diferencias en el tamaño corporal entre colonias para el uso de medidas morfométricas como método de sexado en Spheniscus magellanicus. El Hornero 13: 211-213.

Griffiths, R., M. C. Double, K. Orr and R. J. G. Dawson. 1998. A DNA test to sex most birds. Molecular Ecology 7: 1071-1075.

Lachenbruch, P. A. and M. R. Mickey. 1968. Estimation of error rates in discriminant analysis. Technometrics 10: 1-11.

Mawhinney, K. and T. Diamond. 1999. Sex determination of Great Black-backed Gulls using morphometric characters. Journal of Field Ornithology 70: 206210.

Martínez, I. 1992. Family Spheniscidae (Penguins). Pages 140-172 in Handbook of the Birds of the World, Vol. 1 (J. Del Hoyo, A. Elliott and J. Sargatal, Eds.) Lynx Editions, Barcelona.

Renner, M. and L. Davis. 1999. Sexing Little Penguins Eudyptula minor from Cook Strait, New Zealand using discriminant function analysis. Emu 99: 74-79.

Renner, M., J. Valencia, L. Davis, D. Saez and O. Cifuentes. 1998. Sexing of adult Gentoo Penguins in Antarctica using morphometrics. Colonial Waterbirds 21: 444-449.

Scolaro, J. A. 1987. Sexing fledglings and yearlings of Magellanic Penguins by discriminant analysis of morphometric measurements. Colonial Waterbirds 10: 50-54.

Scolaro, J. A., M. Hall and I. M. Ximénez. 1983. The Magellanic Penguin (Spheniscus magellanicus): Sexing adults by discriminant analysis of morphometric characters. Auk 100: 221-224.

Scolaro, J. A., Z. B. Stanganelli, H. Gallelli and D. F. Vergani. 1990. Sexing of adult Adélie penguins by discriminant analysis of morphometric measurements. Pages 543-549 in Selected scientific papers of the Scientific Committee of CCAMLR, Hobart, Australia.

Tella, J. L., M. G. Forero, M. Bertellotti, J. A. Donázar, G. Blanco and O. Ceballos. 2001. Offspring body condition and immunocompetence are negatively affected by high breeding densities in a colonial seabird: a multi-scale approach. Proceedings of the Royal Society of London B, 268: 1455-1461.

Yorio, P., E. Frere, P. Gandini and G. Harris. 1998. Atlas de la distribución reproductiva de aves marinas en el litoral patagónico argentino. Fundación Patagonia Natural, Puerto Madryn, Argentina.

Zavalaga, C. B. and R. Paredes. 1997. Sex determination of adult Humboldt Penguins using morphometric characters. Journal of Field Ornithology 68: 102-112. 